\title{
China debates university reform
}

\section{Academics lobby for more autonomy, but fear losing powerful connections with government.}

Most scientists in China agree that their university system is ripe for reform. They chafe under bureaucracy and targets that promote research quantity over quality. Now the government has asked them for ideas about how to achieve that reform - and sparked a heated debate.

At issue is the desire of many academics to secure greater autonomy for their institutions, allowing them to hire more freely and develop unique research specialities. But some argue that this autonomy will go hand in hand with losing crucial connections - and influence with powerful government departments.

On 28 February, China revealed its National Outline for Medium and Long Term Educational Reform and Development, which will guide education over the next decade. The plan, open for public consultation until the end of March, says that annual investment in education should increase to $4 \%$ of gross domestic product (from $3.48 \%$ in 2008), and also calls for proposals for university reform that will make the higher-education sector more internationally competitive. On 5 March, Premier Wen Jiabao said that the plan should be implemented "promptly" once the consultation is over.

Rao Yi, dean of Peking University's School of Life Sciences, and Shi Yigong, dean of Tsinghua University's School of Life Sciences in Beijing, had already set out their own ideas for reform the previous week in an article in the Renmin Ribao (People's Daily), the Communist party's daily newspaper. It was an abbreviated version of "Universities should be cultivating their a letter sent to the premier, with whom they had previously discussed the matter, suggesting that the same autonomy that had been bestowed on Chinese agriculture and businesses in the 1980s, and led to rapid economic success, should also be granted to education. The scientists - who both returned to China after successful careers abroad — argue that micromanagement by university administrators acting on instructions from central government forces all universities to chase the same targets, leading to a "monotony of purpose". "Evaluating schools without much research capacity, whose strengths might lie elsewhere, by the number of papers produced could lead to rushed and exaggerated results," Shi and Rao wrote. Instead, "different universities should be cultivating their individual strengths".

By setting common targets regardless of size or resources, the Ministry of Education encourages a harmful standardization, agrees Rao Zihe, president of Nankai University in Tianjin. "Universities watch each other's success in living up 


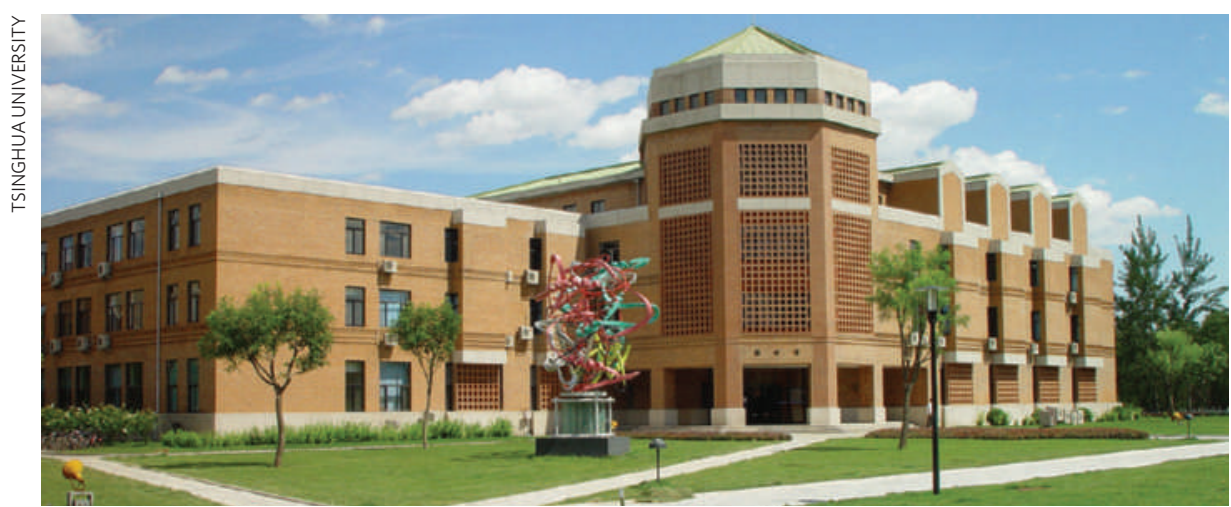

Could Tsinghua University's School of Life Sciences benefit from more freedom from government?

to that standard. Sooner or later, they all start cloning each other," he says.

The education ministry also determines how many students each university should admit, and the basic curricula. These decisions, too, should devolve to the universities, say Shi and $\mathrm{Rao} \mathrm{Yi}$, with a board of directors drawn from the faculty able to oversee the process. This board would also select the university's president — subject to ministry approval — and individual faculties should have the freedom to decide who to appoint as professors.

China has the third-largest national science budget in the world, but most observers agree that results have not been commensurate with investment. A report released in February by the Institute of Scientific and Technical Information of China ranked its homeland 13th out of 19 countries assessed for their "global science influence". Some scientists contacted

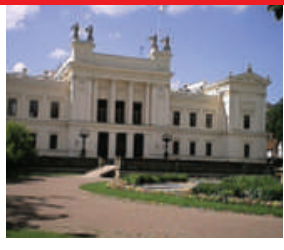

\section{A TALE OF TWO}

SCANDINAVIAN CITIES

Funding changes trigger

hiring in Lund but firing in

Copenhagen.

go.nature.com/3DRKUx

by Nature suggest that trimming the influence of university bureaucrats with close ties to the ministry could help to tame the obsession with publication targets. The question is how.

One suggestion is to end the practice, started in 1999, of bestowing the administrative rank of vice-minister on the presidents of China's 31 leading universities. The titles are meant to recognize the importance of universities. "But some say it poisons the academic culture," says Xue Lan, a science-policy expert at Tsinghua University. "Professors come to think of rank rather than academic standards."

Such a change would signal that universities were focusing more on teaching and research, and less on administrative targets. But in a society that lauds Confucianism, with its emphasis on social hierarchy, a vice-minister post is a mark of a university's importance. "For university presidents, it gives them some power to relate to those outside academia," says Rao Yi.

Xue acknowledges that the status of viceminister can be useful for university administrators. "No matter where you go in China, people pay attention to rank."

David Cyranoski 